\title{
Third Trimester
}

National Cancer Institute

\section{Source}

National Cancer Institute. Third Trimester. NCI Thesaurus. Code C92896.

The period of gestation that ranges from the 28th week of pregnancy until delivery. 